\title{
Prevalence and Possible Predictors of Drug- Resistant Pseudomonas aeruginosa in External Ocular Infections: A Single-Center, Retrospective, Cross-Sectional Study
}

\author{
Ken-ichi Sato ${ }^{1}$ \\ 1. Ophthalmology, Nikko Memorial Hospital, Muroran, JPN \\ Corresponding author: Ken-ichi Sato, vze04311@nifty.ne.jp
}

\section{Abstract \\ Objective}

Ocular infections due to multi-drug-resistant Pseudomonas aeruginosa (MDRP) have been reported in recent years. This study was undertaken to determine the culture-positivity rate of P. aeruginosa and drug resistance among patients with suspected external ocular infections and to predict systemic risk factors for drug resistance in P. aeruginosa.

\section{Methods}

This retrospective, single-center, cross-sectional study involved 781 consecutive patients who provided samples for aerobic culture to test for a suspected external ocular infection. DRP was defined as a strain resistant to one or two of three antibiotics, levofloxacin, gentamicin, and imipenem; MDRP was defined as that which was resistant to all three.

\section{Results}

Among 108 patients in whom gram-negative bacilli were observed, P. aeruginosa was isolated from nine patients, including three DRP-positive cases; no MDRP was isolated. P. aeruginosa was not isolated from those $<69$ years of age. Among patients in whom gram-negative bacilli were detected, the isolation rate of P. aeruginosa was 0 for patients aged $\leqslant 64$ and 0.1 for those aged $\geqslant 65$, indicating a significant difference. For patients with gram-negative bacilli, the DRP-positivity rate was significantly higher for hospitalized patients than outpatients. Thus, in addition to being geriatric, being hospitalized was a risk factor for DRP infection among patients with gram-negative bacilli. All the P. aeruginosa strains isolated were susceptible to colistin.

\section{Conclusions}

Received 01/13/2020 Review began 01/27/2020 Review ended 05/05/2020 Published 05/13/2020

\section{() Copyright 2020}

Sato. This is an open access article distributed under the terms of the Creative Commons Attribution License CC-BY 4.0., which permits unrestricted use, distribution, and reproduction in any medium, provided the original author and source are credited.
Our findings may suggest that once gram-negative bacilli are isolated in an elderly hospitalized patient, possible DRP infection and the topical use of colistin should be taken into consideration even before the results of culture and susceptibility testing are obtained.

Categories: Ophthalmology, Infectious Disease

Keywords: pseudomonas aeruginosa, anti-infective agents, risk factors, eye infections, drug resistance

\section{Introduction}

Pseudomonas aeruginosa is a common gram-negative bacillus often found in moist environments. $P$. aeruginosa rarely causes infectious disease in healthy individuals but is responsible for about $10 \%-20 \%$ of nosocomial infections such as sepsis in intensive care units and wound infections, as well in burns and cystic fibrosis $[1,2]$. Generally, $P$. aeruginosa is resistant to many antibiotics but is known to be susceptible to three classes of antimicrobials: fluoroquinolones, carbapenems, and aminoglycosides.

Since the late 1980 s, more strains resistant to three or more classes of antimicrobials have emerged (specifically, fluoroquinolones, carbapenems, and aminoglycosides), and have been termed multiresistant or multi-drug-resistant P. aeruginosa (MDRP) [3]. The incidence of MDRP infections is still increasing and is associated with increased morbidity, mortality, and costs $[4,5]$.

In terms of ocular infections, $P$. aeruginos $a$ can cause conditions such as keratitis and endophthalmitis $[6,7]$. Although ocular MDRP infections have been reported in recent years, only a few studies have investigated focal risk factors for these ocular infections [8-10].

In light of these issues regarding MDRP, the susceptibility of all isolated P. aeruginosa strains to colistin, 


\section{Cureus}

which has been reported to be effective for treating MDRP infections, was investigated in the ophthalmology department of Nikko Memorial Hospital between April 2013 and September 2018 [11]. Subsequently, this retrospective study was undertaken with the aim of determining the culture-positivity rate of $P$. aeruginosa and drug resistance among patients with suspected external ocular infections and to clarify systemic risk factors for drug resistance in $P$. aeruginosa.

\section{Materials And Methods}

This retrospective, single-center, cross-sectional study involved 781 consecutive patients who visited the Department of Ophthalmology, Nikko Memorial Hospital (Muroran, Hokkaido, Japan) between April 2013 and September 2018, and provided samples (conjunctival swabs or pus out of the lacrimal sac) for aerobic culture to test for a suspected external ocular infection (Table 1).

\begin{tabular}{|c|c|c|}
\hline Sex & Age (years) & Outpatient/inpatient (n) \\
\hline 290 males/491 females & $64 \pm 26($ mean \pm SD); range 0-97; median 72 & $712 / 69$ \\
\hline \multicolumn{3}{|c|}{ TABLE 1: Characteristics of 781 patients with external ocular infection } \\
\hline \multicolumn{3}{|c|}{ All inpatients were hospitalized for conditions other than ophthalmic disorders. } \\
\hline
\end{tabular}

Informed consent was obtained from all patients before the examination. The study adhered to the tenets of the Declaration of Helsinki and was approved by the Ethics Committee of Nikko Memorial Hospital.

To identify clinical risk factors, a systematic review of patients' medical history was carried out by interview in addition to obtaining information from medical records of the hospital. Bacterial culture, identification, and susceptibility testing were outsourced to Daiichi Kishimoto Clinical Laboratories, Inc. (Sapporo, Hokkaido, Japan), where the M100-S19 guidelines from the Clinical and Laboratory Standards Institute (Wayne, PA) were used for interpretation of the antimicrobial susceptibility results. For 142 patients with two or more culture tests, only the first result was included in this study; 220 tests were ultimately excluded.

In this study, DRP was defined as a strain resistant to one or two of three antibiotics, levofloxacin, gentamicin, and imipenem; MDRP was defined as that resistant to all three.

Data analysis was performed using StatView 5.0 (SAS Institute, Inc., Cary, NC) with significance set at $5 \%$. Fisher's exact test was used for statistical analysis.

\section{Results}

Gram-negative bacilli were observed in 108 patients, among whom 12 were hospitalized for conditions other than ophthalmic disorders. Those identified as being infected with gram-negative bacilli were divided into two groups by age: the first $\leqslant 6$ years of age and the second aged $\geqslant 32$ years (Figure 1 ). 


\section{Cureus}

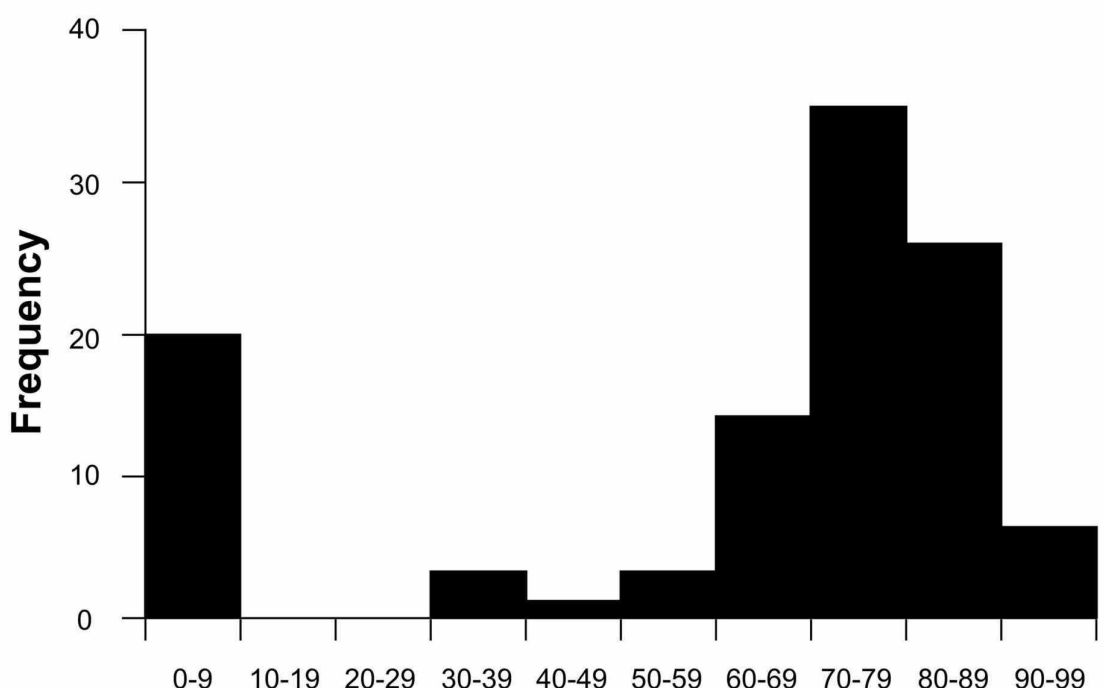

Age (years)

\section{FIGURE 1: Age distribution of patients in whom gram-negative bacilli} were isolated

P. aeruginosa was isolated from nine patients, all of whom were $\geqslant 69$ years of age (Table 2). When gramnegative bacilli were detected, the isolation rate of $P$. aeruginosa was $0(0 / 34 ; 95 \%$ CI $0-0.08)$ for patients aged $\leqslant 64$ and $0.1(9 / 74 ; 95 \% \mathrm{CI} 0.06-0.2)$ for those aged $\geqslant 65$, indicating a significant difference $(P=0.028)$.

\begin{tabular}{|c|c|c|c|c|c|c|c|c|}
\hline \multirow{2}{*}{$\begin{array}{l}\text { Patient } \\
\text { no. }\end{array}$} & \multirow{2}{*}{$\begin{array}{l}\text { Age } \\
\text { (years)/sex }\end{array}$} & \multirow{2}{*}{ Ophthalmic disorder } & \multirow{2}{*}{ Background } & \multirow{2}{*}{ Inpatient } & \multicolumn{4}{|c|}{ Susceptibility } \\
\hline & & & & & LVFX & GM & IPM & CL \\
\hline 1 & 72/female & Dacryocystitis & Granulomatosis with polyangiitis, immunosuppressants & No & $\mathbf{R}$ & $\mathrm{S}$ & $\mathrm{S}$ & $\mathrm{S}$ \\
\hline 2 & $69 /$ male & Dacryocystitis & Rhinosinusitis & No & $\mathrm{S}$ & $\mathrm{S}$ & $\mathrm{S}$ & $\mathrm{S}$ \\
\hline 3 & 80/female & Bacterial keratitis & Peripheral ulcerative keratitis, topical steroid & No & $\mathrm{S}$ & $\mathrm{S}$ & $\mathrm{S}$ & $\mathrm{S}$ \\
\hline 4 & $81 /$ male & Exposure keratitis & Cerebral infarction, dysphagia, gastrogavage & Yes & $\mathbf{R}$ & $\mathrm{I}$ & $\mathrm{S}$ & $\mathrm{S}$ \\
\hline 5 & 74/female & Conjunctivitis & Esophageal and pharyngeal cancer, chemotherapy & No & $\mathrm{S}$ & $\mathrm{S}$ & $\mathrm{S}$ & $\mathrm{S}$ \\
\hline 6 & 95/temale & Conjunctivitis & $\begin{array}{l}\text { Breast cancer, gastrointestinal stromal tumor, cerebral } \\
\text { infarction, gastrogavage }\end{array}$ & Yes & $\mathrm{S}$ & $\mathrm{S}$ & $\mathrm{S}$ & $\mathrm{S}$ \\
\hline 7 & $76 /$ male & Conjunctivitis & Abdominal aortic aneurysm, fungemia & Yes & $\mathrm{R}$ & $\mathrm{S}$ & $\mathbf{R}$ & $\mathrm{S}$ \\
\hline 8 & 84/temale & obstruction & Lacrimal hyposecretion & No & $\mathrm{S}$ & $\mathrm{S}$ & $\mathrm{S}$ & $\mathrm{S}$ \\
\hline 9 & 78/male & $\begin{array}{l}\text { Nasolacrimal duct } \\
\text { obstruction }\end{array}$ & Rhinosinusitis, diabetes mellitus & No & $\mathrm{s}$ & $\mathrm{s}$ & $\mathrm{S}$ & $\mathrm{S}$ \\
\hline
\end{tabular}

TABLE 2: Patients in whom Pseudomonas aeruginosa was isolated

LVFX, levofloxacin; GM, gentamicin; IMP, imipenem; CL, colistin; R, resistant; S, susceptible; I, intermediate.

DRP was isolated from three patients: one outpatient and two inpatients. No MDRP was isolated in this study. Analyzing the patients with gram-negative bacilli, the DRP-positivity rate was 0.2 (2/12; 95\% CI 0.020.5 ) for hospitalized patients and 0.01 (1/96; $95 \%$ CI 0.0003-0.06) for outpatients, and this difference was 
significant $(P=0.032)$.

All the $P$. aeruginosa strains were susceptible to colistin.

\section{Discussion}

Because bacterial properties can change from year to year, guidelines sometimes have to be developed in a relatively short period of time using only a small number of cases. Especially in single-institution studies, it may take time to collect enough positive cases. The current small study is considered to have significance as a method for developing a countermeasure for clinically important bacteria at each facility.

Several risk factors for nosocomial systemic infections caused by MDRP have been reported including age; severity index; being bedridden; transfer from other units; nasogastric feeding; urinary catheterization; mechanical ventilation; intensive care unit stay; and exposure to broad-spectrum antibiotics such as fluoroquinolones, aminoglycosides, and beta-lactams including carbapenems [12-14]. However, it is often difficult to readily obtain this systematic information because patients with suspected MDRP infection tend to have a long medical history and would have received various treatments in multiple hospitals and departments. This impedes immediate clinical decision-making in outpatient care. However, the factor of being hospitalized, which was investigated in the present study, can be easily determined without examining a complicated medical history.

In this study, among patients in whom gram-negative bacilli were isolated, the prevalence of DRP was higher in those who were hospitalized and elderly. The factor of being hospitalized may represent various other known risk factors associated with intensive medical interventions. These two factors, being hospitalized and being elderly, could possibly be adopted as simple predictors of DRP.

Colistin was used in the 1960s and 1970s for treating infections caused by gram-negative bacteria. In spite of the high susceptibility of these bacteria to colistin, it has not been used widely since the early 1980s mainly because of its nephrotoxicity and the subsequent emergence of other broad-spectrum antimicrobials [15]. Later, in addition to its use against gram-negative rods including MDRP in systemic disorders, colistin was refocused as an antimicrobial against MDRP in ocular infections $[8,10,11,16]$.

All the DRP strains isolated in the present study were susceptible to colistin. Thus, our findings may suggest that once gram-negative bacilli are isolated in an elderly hospitalized patient, a possible DRP infection and the topical use of colistin should be taken into consideration even before the results of culture and susceptibility testing are obtained.

Although colistin is usable particularly in countries and regions where it is commercialized as an ophthalmic formulation, careful and reasonable use of colistin is necessary to minimize the induction of colistinresistant $P$. aeruginosa. Understandably, to prevent accelerating acquisition of resistance, caution should also be exercised in the ongoing empirical use of other classes of antimicrobial agents such like fluoroquinolones and aminoglycosides.

This study has certain limitations. First is that because of the single-center, cross-sectional design, the study did not investigate regional variations in bacterial infections or epidemiological changes over time. Therefore, the results are not universally applicable. Second, the number of patients with $P$. aeruginosa infection was small, and so a larger multi-center study is required.

\section{Conclusions}

In summary, 781 consecutive patients provided samples for aerobic culture to test for a suspected external ocular infection. Among 108 patients in whom gram-negative bacilli were observed, P. aeruginosa was isolated from nine patients, including three DRP-positive cases; no MDRP was isolated. In addition to being geriatric, being hospitalized was a risk factor for DRP infection among patients with gram-negative bacilli. All the P. aeruginosa strains isolated were susceptible to colistin.

\section{Additional Information \\ Disclosures}

Human subjects: Consent was obtained by all participants in this study. Ethics Committee of Nikko Memorial Hospital issued approval 104. Animal subjects: All authors have confirmed that this study did not involve animal subjects or tissue. Conflicts of interest: In compliance with the ICMJE uniform disclosure form, all authors declare the following: Payment/services info: All authors have declared that no financial support was received from any organization for the submitted work. Financial relationships: All authors have declared that they have no financial relationships at present or within the previous three years with any organizations that might have an interest in the submitted work. Other relationships: All authors have declared that there are no other relationships or activities that could appear to have influenced the submitted work. 


\section{References}

1. Morrison AJ Jr, Wenzel RP: Epidemiology of infection due to Pseudomonas aeruginosa . Rev Infect Dis. 1984, 6:s627-s642. 10.1093/clinids/6.Supplement_3.S627

2. Carmeli Y, Troillet N, Eliopoulos GM, Samore MH: Emergence of antibiotic-resistant Pseudomonas aeruginosa: comparison of risks associated with different antipseudomonal agents. Antimicrob Agents Chemother. 1999, 43:1379-1382. 10.1128/AAC.43.6.1379

3. Harris A, Torres-Viera C, Venkataraman L, DeGirolami P, Samore M, Carmeli Y: Epidemiology and clinical outcome of patients with multiresistant Pseudomonas aeruginosa. Clin Infect Dis. 1999, 28:1128-1133. $10.1086 / 514760$

4. National Nosocomial Infections Surveillance System: National Nosocomial Infections Surveillance (NNIS) System report, data summary from January 1992 through June 2004, issued October 2004. Am J Infect Control. 2004, 32:470-485. 10.1016/j.ajic.2004.10.001

5. Carmeli Y, Troillet N, Karchmer AW, Samore MH: Health and economic outcomes of antibiotic resistance in Pseudomonas aeruginosa. Arch Intern Med. 1999, 159:1127-1132. 10.1001/archinte.159.10.1127

6. Stapleton F, Carnt N: Contact lens-related microbial keratitis: how have epidemiology and genetics helped us with pathogenesis and prophylaxis. Eye. 2012, 26:185-193. 10.1038/eye.2011.288

7. Endophthalmitis Vitrectomy Study Group: Microbiologic factors and visual outcome in the Endophthalmitis Vitrectomy Study. Am J Ophthalmol. 1996, 122:830-846. 10.1016/S0002-9394(14)70380-0

8. Samant P, Ramugade S: Successful use of intravitreal and systemic colistin in treating multidrug resistant Pseudomonas aeruginosa post-operative endophthalmitis. Indian J Ophthalmol. 2014, 62:1167-1170. 10.4103/0301-4738.126991

9. Vazirani J, Wurity S, Ali MH: Multidrug-resistant Pseudomonas aeruginosa keratitis: risk factors, clinical characteristics, and outcomes. Ophthalmology. 2015, 122:2110-2114. 10.1016/j.ophtha.2015.06.007

10. Jain R, Murthy SI, Motukupally SR: Clinical outcomes of corneal graft infections caused by multi-drug resistant Pseudomonas aeruginosa. Cornea. 2014, 33:22-26. 10.1097/ICO.0000000000000011

11. Berlana D, Llop JM, Fort E, Badia MB, Jódar R: Use of colistin in the treatment of multiple-drug-resistant gram-negative infections. Am J Health Syst Pharm. 2005, 62:39-47. 10.1093/ajhp/62.1.39

12. Defez C, Fabbro-Peray P, Bouziges N, Gouby A, Mahamat A, Daurès JP, Sotto A: Risk factors for multidrugresistant Pseudomonas aeruginosa nosocomial infection. J Hosp Infect. 2004, 57:209-216. 10.1016/j.jhin.2004.03.022

13. Cao B, Wang H, Sun H, Zhu Y, Chen M: Risk factors and clinical outcomes of nosocomial multi-drug resistant Pseudomonas aeruginosa infections. J Hosp Infect. 2004, 57:112-118. 10.1016/j.jhin.2004.03.021

14. Aloush V, Navon-Venezia S, Seigman-Igra Y, Cabili S, Carmeli Y: Multidrug-resistant Pseudomonas aeruginosa: risk factors and clinical impact. Antimicrob Agents Chemother. 2006, 50:43-48. 10.1128/AAC.50.1.43-48.2006

15. Evans ME, Feola DJ, Rapp RP: Polymyxin B sulfate and colistin: old antibiotics for emerging multiresistant gram-negative bacteria. Ann Pharmacother. 1999, 33:960-967. 10.1345/aph.18426

16. Martis N, Leroy S, Blanc V: Colistin in multi-drug resistant Pseudomonas aeruginosa blood-stream infections: a narrative review for the clinician. J Infect. 2014, 69:1-12. 10.1016/j.jinf.2014.03.001 